\title{
Kadir Has Üniversitesi Merkez Kütüphanesi Kuruluşu, Gelişimi ve Hizmetleri
}

Kadir Has University Library History and Services

Şule Yilmaz

Öz

Bu makalede Kadir Has Üniversitesi Cibali Merkez Kütüphanesi'nin kuruluşu, gelişimi, verdiği hizmetleri ve gerçekleştirmek istediği hedefleri anlatimaktadir.

Anahtar sözcükler: Üniversite kütüphaneleri, Kütüphane tanitımı, Kütüphane hizmetleri, Kadir Has Üniversitesi Cibali Merkez Kütüphanesi.

\section{Abstract}

This paper described the Kadir Has University Cibali Central Library's history, development, mission, services and future aims.

Keywords: University libraries. Library publicity. Library services, Kadir Has University Cibali Central Librany.

\section{Giriş}

Kadir Has Üniversitesi 1997 tarihinde 4263 sayıllı yasa ile kurulmuştur. Üniversitemizin ilk kampusu Selimpaşa beldesinde inşa edilmiş, Cibali'deki Tekel'e ait eski Tütün İşleme ve Sigara Fabrikası hükümet kararı ile merkez kampüsü olarak kullanılmak üzere Kadir Has Üniversitesine verilmiştir. Halen eğitime, Cibali Merkez Kampusu başta olmak üzere Selimpaşa Kampusu, Gayrettepe Kampusu, Bahçelievler Kampusu ve Tuzla Hasan Yelmen Kampusunde devam edilmektedir.

Kütüphanecı : Kadir Has Üniversitesi Kütüphane ve Dokümantasyon Darre Başkanlig̈r

(syylmaz@khas.edu.tr) 
Her bir kampusde şube kütüphaneleriyle hizmet vermeye devam eden Kütüphanenin amacı; geleneksel kütüphane hizmetlerini en yeni teknolojik gelişmelerle destekleyerek, kullanıcıların bilgi ihtiyaçlarını mümkün olan en kısa sürede ve maksimum düzeyde karşılamak, eğitim-öğretim ve bilimsel araştırma-geliştirme faaliyetlerinin aft yapısını oluşturmak, bu yolla tüm kütüphane kullanıcılarının bilimsel ve entellektüel faaliyetlerine destek veren kaliteli bir bilgi hizmeti üretmektir.

\section{Kadir Has Üniversitesi Merkez Kütüphanesinin Kuruluşu ve Gelişìm Süreci}

- 1998 Kasım; Gayrettepe Kampusunde kütüphane kuruluş çalışmaları ve koleksiyon oluşturma çalıșmalarına başlanmıştır.

- 1999 yılında; BLISS-PC otomasyon programı satın alınmıs ve geriye dönük MARC formatında kayıt girişleri yapıımıştır. Sınıflama işlemleri için LC Classification Plus CD sürümü satın alınmıştır.

- 2000 yılında Gayrettepe Tıp Kütüphanesi oluşturularak Merkez Kütüphane, Selimpaşa Kampusune taşınmıştı ve kullanıcı için bilgisayar sayısı 4'e çıkarılmıştır. Aynı yıı, kütüphanenin Web sitesi ${ }^{*}$ hazırlanarak Internet'e açılmış, Konsorsiyuma katılarak Proquest Medical and Health Package Online veri tabanına abone olunmuştur. Ayrıca satın alma, koleksiyon geliştirme ve okuyucu hizmetleri politikaları hazırlanmıştır.

- 2001 yılında Selimpaşa Kampusundaki kütüphane, Hazırlık Okulu Kütüphanesine dönüştürüjmüş, Merkez Kütüphane Bahçelievler Kampusune taşınmıştır.

- Şubat 2002 yılında Merkez Kütüphane, Cibali Kampusundeki bin metrekarelik binaya geçmiş ve aynı anda 177 kullanıcıya hizmet verecek şekilde düzenlenerek hizmete girmiştir.

Kullanıcıların bilgi ihtiyaçlarının ulusal ve uluslararası düzeyde kısa sürede, etkin bir biçimde herhangi bir sınırlama olmaksızın karşılanması için kü-

"Kadir Has Universitesi Kütüphanesi. htto:" www khas.edu tr kutuphane. 
tüphanede 16 adet kullanıcı bilgisayarı (Sun Microsystems Tin Client) yerleştirilmiştir. Bunlardan İnternet taraması, cd-rom taraması, çevrim içi veri tabanlarına erişim olanağının yanı sıra diğer üniversite ve bilgi merkezlerine ulaşım da sağlanmıştır.

Basılı dergi abonelikJeri yapılmış ve elektronik dergi abonelikleri için çalışmalar başlatılmıştır.

\section{Koleksiyon}

Kullanıcıların ihtiyaç duyduğu ve duyabileceği her türlü basılı veya elektronik ortamda, görsel ya da işitsel bilgi kaynağı sağlanmaya çalışılmaktadır.

Kütüphane koleksiyonunda Temmuz 2002 sonu itibarıyle 7577 adet kitap (9303 kopya), 61 adet ses kaseti (90 kopya), 108 adet video kaseti (136 kopya), 33 adet disket ( 67 kopya), 18 adet tez, 81 adet cd-rom bulunmaktadır. $\mathrm{Bu}$ sayı, son zamanlardaki yoğun satın alma ve bağışlarla hızıı bir artış göstermektedir.

Amerikan Kültürü ve Edebiyatına ait çok özel 101 adet video kaset ve konuşan kitap koleksiyonu kütüphane tarafından muhafaza edilmektedir. Ayrıca 15 adet Türkçe süreli yayın 10 adet de günlük gazete aboneliği devam etmektedir.

\section{Bina}

Kadir Has Üniversitesi Kütüphanesi, Kasım 1998'de $20 \mathrm{~m}^{2}$ lik bir alanda hizmet vermeye başlamıs, 2002 Şubat'ında $1000 \mathrm{~m}^{2}$ lik bir alan kapasitesine ulaşmıştır. Kütüphane, okuma salonu ( 62 kişilik), süreli yayınlar salonu (51 kişilik), bireyseł çalışma odası ( 24 kişilik), video-müzik odası (24 kişilik) ve 16 adet bilgisayar terminallerinin bulunduğu bölümle birlikte toplam 177 kişilik oturma kapasitesine sahiptir. Ayrıca ödünç verme bankosunun bulunduğu ön salon, Daire Başkanlığı ve personel çalışma odası mevcuttur. Binada NT sunucuya bağlı çalışan personel kutlanımına ayrımış 9 bilgisayar bulunmakta ve merkezi müzik yayını da yapılmaktadır. 


\section{Organizasyon ve Personel}

Merkez Kütüphanede teknik hizmetler, okuyucu hizmetleri ve referans hizmetleri olmak üzere üç birim bulunmaktadır. Bir daire başkanı, iki kütüphaneci, biri yüksekokul mezunu diğeri lise mezunu (akşam saatleri) iki memur görev yapmaktadır. Kütüphane ve Dokümantasyon Daire Başkanlığına bağlı olarak Merkez Kütüphane dışında Tıp Fakültesi Kütüphanesi ve Hazırıłk Okulu Kütüphanesi de hizmet vermektedir.

\section{Kütüphane Hizmetleri}

Kütüphane hizmetleri; teknik hizmetler, okuyucu hizmetleri ve danışma hizmetleri olmak üzere üç ana grupta toplanmıştır. Teknik hizmetler kapsamında sağlama, kataloglama ve sınıflama, okuyucu hizmetleri kapsamında ödünç verme, süreli yayın işlemleri, danışma, referans hizmetleri kapsamında ise elektronik bilgi erişim hizmetleri, kütüphaneler arası işbirliği bulunmaktadir.

Merkez Kütüphanenin açık olduğu saatler hafta içi 08.45-20.30, hafta sonu Cumartesi 10.00-15.30'dur. Yaz dönemi uygulaması ise sadece hafta içi 08.45-17.30 olarak uygulanmaktadır.

\section{Teknik Hizmetler}

Sağlama hizmeti; gelen istekler doğrultusunda ve koleksiyon geliştirme politikasına uygun olarak satın alma yoluyla, bunun yanında kişilerden ve çeşitli kurumlardan gelen bağışlarla yürütülmektedir.

Kütüphanede kataloglama işlemlerinde Anglo Amerikan Kataloglama Kuralları 2, sınıflama işlemlerinde Kongre Kütüphanesi Sınıflandırması (Library of Congress Classification), konu başlıklarında ise Kongre Kütüphanesi Konu Başlıkları (Library of Congress Subject Heading) kullanılmaktadır. Koleksiyon açık raf sistemi ile kullanıma sunulmaktadır.

Ayrıca Kadir Has Üniversitesi Kütüphanesinde kullanılan Türkçe konu başiıkłarı listesi oluşturma çalışmaları devam etmektedir. Kütüphane katało- 
ğuna kaydedilen kaynaklara ait konu başlıkları, hem İngilizce, hem de Türkçe olarak verilmektedir.

Kütüphanemizde otomasyon programı olarak "BLISS-PC" kullanılmakta ve 2001 yılından itibaren kütüphane kataloguna innternet üzerinden de erişim sağlanmaktadır.

\section{Okuyucu Hizmetleri}

Koleksiyonda bulunan danışma kaynakları, gazeteler, süreli yayınlar ve cdrom haricindeki kaynaklar ödünç verilebilmektedir. Üniversite personeli ve öğrencileri 15 gün süre ile 5 kitap, 1 adet ciltli dergi, akademik personel 1 ay süre ile 10 kitap, 2 adet ciltli dergi, yüksek lisans ve doktora öğrencileri ise 20 gün süre ile 5 kitap ve 1 adet ciltli dergi ödünç alma hakkına sahiptirler. 2002 Temmuz ayı sonu itibarıyle Merkez Kütüphane'de 1527 ödünç verme işlemi yapılmışır.

\section{Danışma Hizmetleri}

Kullanıcıların bilgi ihtiyaçlarının ulusal ve uluslararası düzeyde kısa sürede, etkin bir biçimde herhangi bir sınırlama olmaksızın karşılanması için Kütüphanede yer alan 16 adet kullanıcı bilgisayarının tamamından İnternet taraması, cd-rom taraması, çevrim içi veri tabanlarına erişim olanağı sağlanmaktadır. Bu terminallerden, diğer üniversite kütüphaneleri ve bilgi merkezlerine de bağlanmak için de yararlanımaktadır. Danışma kütüphanecisi, katalog taraması, Internet'ten bilgiye ve kaynağa ulaşım, çevrim içi ve cd-rom veri tabanı taramaları ile kullanıcının gereksinim duyduğu bilgi kaynaklarına ve bilgiye ulaşılabilmesi için yardımcı olmaktadır. Ayrıca akademik personele, kütüphaneler arası işbirliği kapsamında diğer üniversitelerin kütüphane ve bilgibelge merkezlerinden ödünç kitap alıp verme, fotokopi sağlama hizmeti de verilmektedir.

Danışma Bölümü tarafından üniversitede eğitim alan bütün bölümlere oryantasyon programı uygulanmaktadır. 2000-2001 ve 2001-2002 eğitim-öğretim döneminde ise Amerikan Kültürü ve Edebiyatı Bölümü ile birlikte "Paral- 
lel Studies" adı altında kütüphane ortamında, görevli bir kütüphaneci tarafından yürütülen bir pilot çalışmaya başlanılmıştır. Bu uygulamanın amacı, öğrencilere kütüphaneyi tanıtarak derslerinde kullanacakları temel ve yardımcı kaynakların neler olduğunu anlatmaktır. Basılı kaynakların yanında elektronik kaynakları da kullanarak araştırmalarında ve derslerindeki bilgi ihtiyaçlarını en etkin ve en kısa sürede nasıl karşılayacaklarını öğretmek ve uygulamalı olarak araştırma yaptırmaktır. 2002-2003 eğitim-öğretim yılında diğer bölümlerin de bu çalışmanın kapsamına alınmasıı planlanmıştır.

Elektronik kütüphanecilik anlayışıyla hazırlanan Kütüphane Web sitesinden güncel duyuru ve katalog tarama hizmeti verilmektedir. Aynı zamanda çevrim içi veri tabanları, Resmi Gazete ve diğer günlük gazeteler, ücretsiz dergiler, elektronik kitaplar ve danışma kaynakların ile diğer bilgi merkezlerine bağlantılar yapılarak gereksinim duyulan bilgilere ulaşı।maya çalışılmaktadir.

\section{Sonuç}

Amacı, geleneksel kütüphane hizmetlerini en yeni teknolojik gelişmelerle destekleyerek, kullanıcıların bilgi ihtiyaçlarını mümkün olan en kısa sürede ve maksimum düzeyde karşılamak, eğitim-öğretim ve bilimsel araştırma-geliştirme faaliyetlerinin alt yapısını oluşturmak ve bu yolla tüm kütüphane kullanıcılarının bilimsei ve entelektüel faaliyetlerine destek veren kaliteli bir kütüphane hizmeti üretmek olan Kadir Has Üniversitesi Merkez Kütüphanesi, kurumsal ve ulusal düzeyde bilim, eğitim ve kültür alanında üzerine düşen tüm görevleri yerine getirmeyi hedeflemektedir.

Bir diğer amacı da elektronik yayın aboneliğini artırmak ve kütüphaneler arası işbirliğini üst seviyede tutarak daha geniş ve etkin bilgi hizmeti sunmaktır.

Bir dünya üniversitesi olmak için üzerine düşen katkıyı yerine getiren Kadir Has Üniversitesi Kütüphanesi; verdiği bilgi hizmetleriyle, sürekli mesleki ve teknolojik gelişmeleri takip eden ve uygulayan elektronik bir bilgi merkezi olmak yolundadır. 